\title{
Effect of Rinsing Canned Foods on Bisphenol-A Exposure: The Hummus Experiment
}

\author{
Brenna E. Blackburn ${ }^{1}$, Kyley J. Cox ${ }^{1}$, Yue Zhang ${ }^{2}$, David J. Anderson ${ }^{3}$, Diana G. Wilkins ${ }^{3,4}$ and \\ Christina A. Porucznik ${ }^{1}$ (D)

\begin{abstract}
${ }^{1}$ Division of Public Health, Department of Family and Preventive Medicine, University of Utah, Salt Lake City, Utah, USA, ${ }^{2}$ Department of Internal Medicine, University of Utah, Salt Lake City, Utah, USA, ${ }^{3}$ Center for Human Toxicology, University of Utah, Salt Lake City, Utah, USA, and ' Department of Pathology, University of Utah, Salt Lake City, Utah, USA

Corresponding author: Christina A. Porucznik Division of Public Health, Department of Family and Preventive Medicine
\end{abstract} \\ 375 Chipeta Way, Suite A Salt Lake City, UT 84108. Phone: 8015873315 Email: christy.porucznik@utah.edu
}

(Received 30 June 2020; Revised 15 September 2020; Accepted 16 September 2020)

\begin{abstract}
Bisphenol-A (BPA) is associated with adverse health outcomes and is found in many canned foods. It is not understood if some BPA contamination can be washed away by rinsing. The objective of this single-blinded crossover experiment was to determine whether BPA exposure, as measured by urinary concentrations, could be decreased by rinsing canned beans prior to consumption. Three types of hummus were prepared from dried beans, rinsed, and unrinsed canned beans. Fourteen healthy participants ate two samples of each hummus over six experimental days and collected spot urine specimens for BPA measurement. The geometric mean BPA levels for dried beans BPA $(\mathrm{GM}=0.97 \mathrm{ng} / \mathrm{ml}, 95 \% \mathrm{CI}=0.74,1.26)$ was significantly lower than rinsed $(\mathrm{GM}=1.89 \mathrm{ng} / \mathrm{ml}, 1.37,2.59)$ and unrinsed $(\mathrm{GM}=2.46 \mathrm{ng} / \mathrm{ml}, 1.44,4.19)$. Difference-in-difference estimates showed an increase in GM BPA from pre- to post-hummus between unrinsed and rinsed canned beans of $1.39 \mathrm{ng} / \mathrm{ml}$, p-value $=0.0400$. Rinsing canned beans was an effective method to reduce BPA exposure.
\end{abstract}

Keywords: Bisphenol A; Food Preparation; Exposure; Endocrine Disruption

\section{Introduction}

Bisphenol A (BPA) - a common chemical used in polycarbonate plastics and epoxy resins frequently used to store food and water (e.g., water bottles, dental sealants, canned foods, bottle caps) -is a known endocrine disruptor. BPA exposure has been associated with impaired reproductive health outcomes including immune dysfunction (Clayton et al., 2011), fertilization implantation failure (Ehrlich et al., 2012), male sexual dysfunction, and altered hormone levels and reduced sperm quality in males (Meeker et al., 2011). Other health outcomes such as hormone-associated cancers (H. Gao et al., 2015), cardiovascular diseases (X. Gao \& Wang, 2014), diabetes (Sun et al., 2014), and asthma (Kim et al., 2014) have also been associated with BPA, but are less established.

A small but innovative crossover study at Harvard University randomly assigned participants to eat fresh soup for lunch daily for five consecutive days and canned soup for five consecutive days (order of soup was blinded) (Carwile et al., 2011). Urinary BPA concentration were over 1,000\% higher during the canned soup ingestion week compared to the same individual's fresh soup consumption week, demonstrating the impact of transient BPA exposures to commercially available foods on concentrations measured in human subjects (Carwile et al., 2011). 


\section{Objective}

It is well established that canned goods are a common source of BPA. However, it is not understood if some BPA contamination can be washed away by rinsing the food prior to ingestion. We performed a single-blinded crossover experiment to determine whether BPA exposure, as measured by urinary concentrations, could be decreased by rinsing canned beans prior to consumption. Because of the quick metabolism of BPA (half-life $\sim 6$ hours), it is reasonable to expect daily variation in measures of exposure and therefore collect samples over multiple days at multiple times of the day (Volkel et al., 2002).

\section{Methods}

Healthy male and female adult volunteers were recruited from among faculty, staff, and students affiliated with The University of Utah Department of Family and Preventive Medicine for this pilotscale study; participants had no known health issues that would affect BPA consumption or metabolism. Volunteers agreed to consume portions of hummus two times a week for three weeks and to provide urine samples in the morning and afternoon on each of 6 experimental days during the 3 -week duration of the study. Hummus was prepared by the same local restaurant for each experimental condition: prepared from dry beans, canned beans that were drained but not rinsed, and canned beans that were drained and rinsed three times for one minute each. Each participant was given one, two-ounce sample of hummus on two consecutive days in a week followed by a washout period of 4-6 days (Figure 1). This was done for all three hummus types.

Total BPA was measured in the urine samples using ultra-high-performance liquid chromatographytandem mass spectrometry (Anderson et al., 2014). In statistical analysis, clustered generalized estimating equations (GEE) with gamma distribution and log link were used to account for three types of hummus with both pre- and post-exposure BPA measurements and multiple measurements per person. The GEE models included indicators for time (pre- or post-hummus), hummus type, and an interaction term between these variables. All models were adjusted for age and sex.

\section{Results}

A total of 14 participants were enrolled, including 10 females and 4 males with a mean age of 28.9. + /6.3 years (Table 1$)$.

There were 161 samples collected of the 168 expected ( $95.8 \%$ compliance). Table 2 shows BPA concentrations by age and sex.

Figure 2 shows the BPA GM for pre- and post-hummus samples by hummus type. There were no significant differences in the BPA GM pre-hummus. The BPA GM post-hummus with dried beans $(\mathrm{GM}=0.97 \mathrm{ng} / \mathrm{ml}, 95 \% \mathrm{CI}=0.74,1.26)$ was significantly lower than the post-hummus measurements for the rinsed canned beans $(\mathrm{GM}=1.89 \mathrm{ng} / \mathrm{ml}, 95 \% \mathrm{CI}=1.37,2.59)$ and the unrinsed canned beans $(\mathrm{GM}=2.46 \mathrm{ng} / \mathrm{ml}, 95 \% \mathrm{CI}=1.44,4.19)$.

As shown in Table 3, both types of canned beans, had significantly increased BPA from the pre- to post-hummus conditions. We did not see a significant increase from pre- to post-hummus with the dried beans $(\beta=0.04 \mathrm{ng} / \mathrm{ml}$, $\mathrm{p}$-value $=0.8628)$. Correspondingly, the DD estimates showed a $1.4 \mathrm{ng} / \mathrm{ml}$ increase in BPA from pre- to post-hummus between unrinsed canned beans and rinsed canned beans ( $\mathrm{p}$ value $=0.0400)$.

\begin{tabular}{|c|c|c|c|c|c|c|c|c|c|c|c|c|c|c|c|c|c|c|c|c|}
\hline Day & $M$ & $T$ & W & Th & $\mathrm{F}$ & Sa & Su & $M$ & $T$ & w & Th & $\mathbf{F}$ & Sa & $\mathrm{Su}$ & $M$ & $T$ & w & Th & F Sa & Su \\
\hline Consume Hummus & & & $\mathrm{x}$ & $x$ & & & & & & & $\mathrm{x}$ & $x$ & & & & & $\mathrm{x}$ & $x$ & & \\
\hline Urine (before lunch, $\sim 5 \mathrm{pm}$ ) & & & $\mathrm{x}$ & $x$ & & & & & & & $x$ & $x$ & & & & & $x$ & $x$ & & \\
\hline Hummus Treatment & & & & $e d b$ & ans & & & & & inse & can & led $t$ & eans & & & & insed & cann & ed beans & \\
\hline
\end{tabular}

Figure 1. Study protocol for crossover hummus consumption. 
Table 1. Demographics of study population.

\begin{tabular}{|c|c|}
\hline $\mathrm{N}(\%)$ & Total $\mathrm{N}=14$ \\
\hline \multicolumn{2}{|l|}{ Age } \\
\hline$<26$ & $4(29.6)$ \\
\hline $26-30$ & $7(50.0)$ \\
\hline$>30$ & $3(21.4)$ \\
\hline \multicolumn{2}{|l|}{ Sex } \\
\hline Male & $4(28.6)$ \\
\hline Female & $10(71.4)$ \\
\hline \multicolumn{2}{|l|}{ BMI } \\
\hline Underweight & $1(7.1)$ \\
\hline Normal & $10(71.4)$ \\
\hline Overweight & $2(14.3)$ \\
\hline Obese & $1(7.1)$ \\
\hline \multicolumn{2}{|l|}{ Race } \\
\hline Caucasian & $8(57.1)$ \\
\hline Other/Multiracial & $4(28.6)$ \\
\hline Missing & $2(14.3)$ \\
\hline \multicolumn{2}{|l|}{ Hispanic } \\
\hline Yes & $4(28.6)$ \\
\hline No & $10(71.4)$ \\
\hline \multicolumn{2}{|l|}{ Household Size } \\
\hline 1 & $6(42.9)$ \\
\hline 2 & $4(28.6)$ \\
\hline 3 & $2(14.3)$ \\
\hline Missing & $2(14.3)$ \\
\hline \multicolumn{2}{|l|}{ Marital Status } \\
\hline Married & $7(50.0)$ \\
\hline Separated & $1(7.1)$ \\
\hline Never Married & $4(28.6)$ \\
\hline Member of Unmarried Couple & $2(14.3)$ \\
\hline \multicolumn{2}{|l|}{ Annual Income } \\
\hline Less than $\$ 19,000$ & $3(21.4)$ \\
\hline$\$ 20,000-\$ 39,000$ & $3(21.4)$ \\
\hline$\$ 40,000-\$ 74,999$ & $0(0.0)$ \\
\hline$\$ 75,000-\$ 99,999$ & $5(35.7)$ \\
\hline Prefer Not to Answer/Unsure & $3(21.4)$ \\
\hline \multicolumn{2}{|l|}{ Employment } \\
\hline Employed for Wages & $2(14.3)$ \\
\hline Student & $12(85.7)$ \\
\hline
\end{tabular}


Table 1. Continued

\begin{tabular}{lc}
\hline $\mathrm{N}(\%)$ & Total N $=14$ \\
\hline Education & $1(7.1)$ \\
\hline Some College or Technical School & $9(64.3)$ \\
\hline Bachelors Degree & $3(21.4)$ \\
\hline Masters Degree & $1(7.1)$ \\
\hline Doctoral Degree & \\
\hline
\end{tabular}

Table 2. Geometric mean BPA concentrations $(\mathrm{ng} / \mathrm{mL})$ by demographic characteristics.

\begin{tabular}{|c|c|c|c|c|c|c|c|c|c|}
\hline & \multicolumn{3}{|c|}{ All samples } & \multicolumn{3}{|c|}{ Pre-hummus } & \multicolumn{3}{|c|}{ Post-hummus } \\
\hline & $\mathrm{n}$ & $\begin{array}{l}n> \\
\text { LLOQ }\end{array}$ & $\begin{array}{c}\text { GM BPA } \\
(95 \% \mathrm{Cl})\end{array}$ & $\mathrm{n}$ & $\begin{array}{l}n> \\
\text { LLOQ }\end{array}$ & GM BPA $(95 \% \mathrm{Cl})$ & $n$ & $\begin{array}{l}n> \\
\text { LLOQ }\end{array}$ & $\begin{array}{l}\text { GM BPA } \\
(95 \% \mathrm{Cl})\end{array}$ \\
\hline Everyone & 161 & 105 & $1.25(1.09,1.44)$ & 82 & 47 & $0.96(0.84,1.11)$ & 79 & 58 & $1.65(1.32,2.07)$ \\
\hline \multicolumn{10}{|l|}{ Age } \\
\hline$<26$ & 47 & 37 & $1.38(1.11,1.72)$ & 24 & 18 & $1.02(0.81,1.27)$ & 23 & 19 & $1.90(1.34,2.69)$ \\
\hline $26-30$ & 79 & 52 & $1.22(1.02,1.45)$ & 40 & 24 & $1.02(0.83,1.26)$ & 39 & 28 & $1.46(1.10,1.93)$ \\
\hline$>30$ & 35 & 16 & $1.18(0.77,1.80)$ & 18 & 5 & $0.79(0.55,1.13)$ & 17 & 11 & $1.80(0.83,3.91)$ \\
\hline \multicolumn{10}{|l|}{ Sex } \\
\hline Male & 48 & 41 & $1.65(1.31,2.07)$ & 24 & 21 & $1.23(0.99,1.53)$ & 24 & 20 & $2.20(1.50,3.22)$ \\
\hline Female & 113 & 64 & $1.12(0.94,1.32)$ & 58 & 26 & $0.87(0.73,1.03)$ & 55 & 38 & $1.45(1.09,1.93)$ \\
\hline
\end{tabular}

$\mathrm{LLOQ}=$ lower limit of quantitation $(0.75 \mathrm{ng} / \mathrm{ml}) \mathrm{GM}=$ geometric mean, $\mathrm{BPA}=$ Bisphenol $\mathrm{A}$.

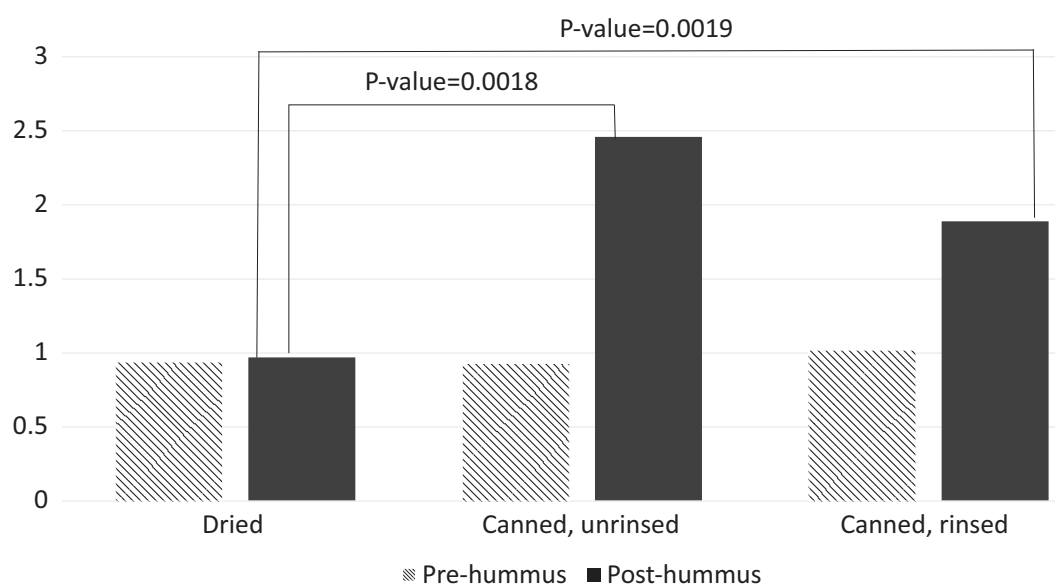

Figure 2. Geometric mean BPA pre- and post-consumption of each hummus type.

\section{Discussion}

Our results matched the hypothesis of a dose-response increase in BPA from dry beans to rinsed canned beans to unrinsed canned beans and highlights rinsing as one potential way for individuals to reduce BPA exposure. As BPA has been associated with many adverse reproductive effects (Clayton et al., 2011; Ehrlich et al., 2012; Tomza-Marciniak et al., 2018), consumers seek to minimize exposure especially 
Table 3. Model estimates from pre- vs post-hummus eating and difference-in-difference results.

\begin{tabular}{lcc} 
& $\begin{array}{c}\text { Pre- vs. post-hummus } \\
\beta \text { estimate }(p-v a l u e)^{*}\end{array}$ & $\begin{array}{c}\text { DD } \beta \text { estimate } \\
(p-v a l u e)^{*}\end{array}$ \\
\hline Dried beans & $0.04(0.8628)$ & $-0.64(0.0097)$ \\
\hline Canned beans, rinsed & $0.59(0.0022)$ & Reference \\
\hline Canned beans, not rinsed & $1.70(0.0008)$ & $1.39(0.0400)$ \\
\hline
\end{tabular}

$\mathrm{DD}=$ difference-in-difference. ${ }^{\star}$ Adjusted for age and sex.

during childhood and reproductive years. While rinsing the beans did not remove all BPA exposure, in adjusted models the estimate from pre- to post-hummus was nearly three (2.88) times lower in the rinsed canned beans compared to the canned beans that were drained but not rinsed.

\section{Conclusions}

It has been well established that consumption of canned foods is associated with increased urinary BPA concentrations (Carwile et al., 2011; Hartle et al., 2016). Further, canned fruits and vegetables (which includes beans) have been reported to be among the canned foods with the highest BPA concentrations along with soups and pasta (Hartle et al., 2016). While it may not be possible to rinse all canned foods, this method has been shown to be effective in our pilot study. This is a cost-effective method that consumers can easily use to reduce BPA exposure. Future studies are needed to examine this with a larger sample size and across other canned foods.

$\begin{array}{ll}\text { Abbreviations } \\ \text { BPA } & \text { Bisphenol A } \\ \text { GM } & \text { Geometric mean } \\ \text { CI } & \text { Confidence interval } \\ \text { LLOQ } & \text { Lower limit of quantitation } \\ \text { GEE } & \text { Clustered generalized estimating equations } \\ \text { DD } & \text { Difference-in-difference }\end{array}$

Authors' contributions. CP: conceived the study idea, obtained funding, assembled the team, and oversaw all aspects of implementation, analysis, and writing. BB: performed statistical analysis and wrote the first draft of the manuscript. YZ: provided statistical consultation. KC: participated in study design, led the implementation, participated in analysis and writing. DA: performed laboratory analyses. DW: oversaw laboratory analysis, quality control and interpretation of laboratory results. All authors approved the manuscript.

Ethics approval and consent to participate. Ethical oversight was provided by The University of Utah Institutional Review Board (IRB\#00080867). Informed consent was obtained by all participants prior to study participation.

Competing interests. The authors declare they have no competing interests

Funding. This project was funded by the Health Studies Fund of the Department of Family and Preventive Medicine at the University of Utah School of Medicine.

Data Availability. Contact the corresponding author for data access.

\section{References}

Anderson, D. J., Brozek, E. M., Cox, K. J., Porucznik, C. A., \& Wilkins, D. G. (2014). Biomonitoring method for bisphenol A in human urine by ultra-high-performance liquid chromatography-tandem mass spectrometry. Journal of Chromatography B, Analytical Technologies in the Biomedical and Life Sciences, 953-954, 53-61. https://doi.org/10.1016/ j.jchromb.2014.01.039 
Carwile, J. L., Ye, X., Zhou, X., Calafat, A. M., \& Michels, K. B. (2011). Canned soup consumption and urinary bisphenol A: A randomized crossover trial. The Journal of the American Medical Association, 306, 2218-2220. https://doi.org/10.1001/ jama.2011.1721

Clayton, E. M., Todd, M., Dowd, J. B., \& Aiello, A. E. (2011). The impact of bisphenol A and triclosan on immune parameters in the U.S. population, NHANES 2003-2006. Environmental Health Perspectives, 119, 390-396. https://doi.org/10.1289/ ehp.1002883

Ehrlich, S., Williams, P. L., Missmer, S. A., Flaws, J. A., Berry, K. F., Calafat, A. M., Ye, X., Petrozza, J. C., Wright, D., \& Hauser, R. (2012). Urinary bisphenol A concentrations and implantation failure among women undergoing in vitro fertilization. Environmental Health Perspectives, 120, 978-983. https://doi.org/10.1289/ehp.1104307

Gao, H., Yang, B.-J., Li, N., Feng, L.-M., Shi, X.-Y., Zhao, W.-H., \& Liu, S.-J. (2015). Bisphenol A and hormone-associated cancers: Current progress and perspectives. Medicine, 94, e211-e211. https://doi.org/10.1097/MD.0000000000000211

Gao, X., \& Wang, H.-S. (2014). Impact of bisphenol a on the cardiovascular system-Epidemiological and experimental evidence and molecular mechanisms. International Journal of Environmental Research and Public Health, 11, 8399-8413. https://doi.org/10.3390/ijerph110808399

Hartle, J. C., Navas-Acien, A., \& Lawrence, R. S. (2016). The consumption of canned food and beverages and urinary bisphenol A concentrations in NHANES 2003-2008. Environmental Research, 150, 375-382. https://doi.org/10.1016/j. envres.2016.06.008

Kim, K.-N., Kim, J. H., Kwon, H.-J., Hong, S.-J., Kim, B.-J., Lee, S.-Y., Hong, Y. C., \& Bae, S. (2014). Bisphenol A exposure and asthma development in school-age children: A longitudinal study. PLoS One, 9, e111383-e111383. https://doi.org/ 10.1371/journal.pone.0111383

Meeker, J. D., Yang, T., Ye, X., Calafat, A. M., \& Hauser, R. (2011). Urinary concentrations of parabens and serum hormone levels, semen quality parameters, and sperm DNA damage. Environmental Health Perspectives, 119, 252-257. https://doi.org/ 10.1289/ehp.1002238

Sun, Q., Cornelis, M. C., Townsend, M. K., Tobias, D. K., Eliassen, A. H., Franke, A. A., Hauser, R., \& Hu, F. B. (2014). Association of urinary concentrations of bisphenol A and phthalate metabolites with risk of type 2 diabetes: A prospective investigation in the Nurses' Health Study (NHS) and NHSII cohorts. Environmental Health Perspectives, 122, 616-623. https://doi.org/10.1289/ehp.1307201

Tomza-Marciniak, A., Stepkowska, P., Kuba, J., \& Pilarczyk, B. (2018). Effect of bisphenol A on reproductive processes: A review of in vitro, in vivo and epidemiological studies. Journal of Applied Toxicology, 38, 51-80. https://doi.org/10.1002/ jat. 3480

Volkel, W., Colnot, T., Csanady, G. A., Filser, J. G., \& Dekant, W. (2002). Metabolism and kinetics of bisphenol A in humans at low doses following oral administration. Chemical Research in Toxicology, 15, 1281-1287. https://doi.org/10.1021/ tx025548t

Cite this article: Blackburn BE, Cox KJ, Zhang Y, Anderson DJ, Wilkins DG, Porucznik CA (2020). Effect of Rinsing Canned Foods on Bisphenol-A Exposure: The Hummus Experiment Experimental Results, 1, e45, 1-10. https://doi.org/10.1017/ exp.2020.52 


\section{Peer Reviews}

\section{Reviewing editor: Prof. Martin Michaelis}

University of Kent, School of Biosciences, Canterbury, United Kingdom of Great Britain and Northern Ireland, CT2 7NJ

This article has been accepted because it is deemed to be scientifically sound, has the correct controls, has appropriate methodology and is statistically valid, and met required revisions.

doi:10.1017/exp.2020.52.pr1

Review 1: Effect of Rinsing Canned Foods on Bisphenol-A Exposure: The Hummus Experiment Reviewer: Dr. Tsu-Nai Wang (iD

Kaohsiung Medical University, Department of Public Health, No.100, Shin-Chuan 1st Road, Sanmin Dist., Kaohsiung City, 80708, Kaohsiung, Taiwan, 807

Date of review: 08 July 2020

(c) The Author(s), 2020. Published by Cambridge University Press This is an Open Access article, distributed under the terms of the Creative Commons Attribution licence (http://creativecommons.org/licenses/by/4.0/), which permits unrestricted re-use, distribution, and reproduction in any medium, provided the original work is properly cited.

Conflict of interest statement. Reviewer declares none

Comments to the Author: This is an interesting and well-written manuscript. There are several comments: The selection criteria of subjects should be mentioned, such as age, non-smoker, non-pregnant and no renal diseases seem to be included. The authors should present the QA/QC data related precision and accuracy to ensure the quality of their measurement. Some studies have suggested to include urinary creatinine-adjusted levels or creatinine as a covariate to avoid overestimation of results. Another suggestion is that, how to prevent the study subjects from exposure to other sources of BPA, such as canned food intake three experimental periods. In the lines 108-9, the authors mentioned that "DD estimate from pre- to post-hummus was four times lower in the rinsed canned beans compared to the canned beans that were drained but not rinsed". The authors did not describe how to calculate the estimation of "four times", and please check the correctness.

\section{Score Card}

Presentation

4.6

Is the article written in clear and proper English? (30\%)

Is the data presented in the most useful manner? (40\%)

Does the paper cite relevant and related articles appropriately? (30\%)

Context

Does the abstract correctly embody the content of the article? (25\%)

Does the introduction give appropriate context? (25\%)

Is the objective of the experiment clearly defined? (25\%) 
Are the limitations of the experiment as well as the contributions of the experiment clearly outlined? (20\%) 


\section{Review 2: Effect of Rinsing Canned Foods on Bisphenol-A Exposure: The Hummus Experiment}

Reviewer: Dr. Jamie Liu

Brown University School of Public Health, Providence, United States, 02903

Date of review: 25 July 2020

(C) The Author(s), 2020. Published by Cambridge University Press This is an Open Access article, distributed under the terms of the Creative Commons Attribution licence (http://creativecommons.org/licenses/by/4.0/), which permits unrestricted re-use, distribution, and reproduction in any medium, provided the original work is properly cited.

Conflict of interest statement. Reviewer declares none

Comments to the Author: I enjoy reading this concise and interesting paper and only have a few questions.

1. What is the eligibility? Any participants had health conditions that could affect BPA metabolism?

2. Was the urine sample for post-hummus collected right after the pre-hummus urine? Could the participants be exposed to BPA via other sources during that time gap? For pre-humus, was there only one urine collection? Can a spot urine explain variations?

3. It seems urinary BPA for pre-hummus was higher in the canned rinsed? Could some factors cause a within-person variation that was not controlled for, e.g. changes in kidney function or a recent dental visit before urine collection?

4. According to Ye 2015 in EHP, regardless of spot or 24-hr collection, urinary BPA concentrations changed considerably within a day and for 7 days, collecting urine samples in the morning and afternoon for each treatment may not account for such variations.

5. It would be more informative to stratify the analysis by age and sex if sample size allows.

6. SES could contribute to the levels of BPA. I was wondering if the authors have examined the associations between SES and BPA, and whether SES should be included in the models.

7. I was wondering if the concentrations of BPA in the original canned beans used to make hummus for both treatment groups are the same?

8. Could the authors discuss the findings from previous papers and compare the urinary levels of BPA among studies, and include limitations and advantages?

\section{Score Card}

Presentation

Is the article written in clear and proper English? (30\%)

Is the data presented in the most useful manner? (40\%)

Does the paper cite relevant and related articles appropriately? (30\%)

\section{Context}

Does the title suitably represent the article? (25\%)

Does the abstract correctly embody the content of the article? (25\%)

Does the introduction give appropriate context? (25\%)

Is the objective of the experiment clearly defined? (25\%) 
Analysis

2.8

Does the discussion adequately interpret the results presented? (40\%)

Is the conclusion consistent with the results and discussion? (40\%)

Are the limitations of the experiment as well as the contributions of the experiment clearly outlined? (20\%) 